\title{
—米 \\ NOTAS SOBRE A RELAÇÃO ENTRE VARIÁVEIS SOCIAIS E ORGANIZAÇÃO ESPACIAL: UMA EXPERIÊNCIA DE PESQUISA NA CIDADE DE IMPERATRIZ-MA
}

\section{- JESUS MARMANILLO PEREIRA*}

Resumo: 0 presente artigo traz reflexões e observações a respeito da utilização de diferentes tipos de fontes visuais para pensar algumas possibilidades de interpretação sobre grupos urbanos e setores da cidade de Imperatriz-MA. Por meio de uma narrativa orientada por teorias que privilegiam a relação entre variáveis espaciais e sociais, utilizou-se um conjunto de fotografias, de diálogos com moradores e de observações diretas para interpretar aproximações, distanciamentos e concentrações que constituem a dinâmica urbana dessa cidade, a segunda maior do estado do Maranhão. A cidade foi pensada de acordo com três situações, escalas e níveis, e verificou-se a necessidade de refletir sobre a geometrização do olhar para os mais diferentes tipos de fontes e situações postas no fazer etnográfico.

Palavras-chave: Geometrização; Escalas; Imagens; Grupos urbanos.

Introdução

A partir da própria definição linguística de imagem, nota-se que 0 dicionário Aurélio (2002) a entende enquanto representação gráfica, mental, plástica ou fotográfica de pessoa ou de objeto, podendo ser também uma lembrança ou recordação. Em caminho semelhante, o Houaiss(2001) define imagem como uma representação da forma, aspecto pelo qual um ser é percebido, uma representação de um objeto que emite ou recebe luz e que é formado por vários raios luminoso que passam por nosso sistema óptico. 
As imagens podem ser entendidas por seus aspectos físico-químicos,com percepção desenvolvida por meio da luz, e pelos aspectos subjetivos de quem a produz, pois o processo cognitivo de geometrizar ideias constitui parte fundamental do processo que fornece sentido às imagens, possibilitando um primeiro passo para compreender os mecanismos de construção de narrativas, ou seja, mais que registros literais, a operação metodológica com imagens deve ser desenvolvida, antes de tudo, no campo da fenomenologia e das ideias. Sobre isso, Samain (2012) percebe que 0 poder heurístico das fontes imagéticas é estimulado, quando associado a elementos externos como memória e outras fontes. Se, por um lado, a capacidade de ideação das imagens é um importante dado, inclusive para a explicação físico-química da suaprodução e recepção, por outro, dialoga, em grande medida, com outros dados e ideias.

Nesse sentido, a hipótese do presente texto é que, independentemente das escalas e perspectivas, as análises com imagens são orientadas visualmente por referências espaciais, ou seja, constituem um tipo de "jogo", cujas regras parecem ser baseadas na compreensão das lógicas das disposições e localizações: aproximações, semelhanças, distanciamentos, diferenças e limites. Nesse âmbito de geometrização
(BACHELARD, 1996), o presente texto visa demonstrar algumas similaridades analíticas e possibilidades de interpretação visual sobre grupos urbanos por meio de diferentes formas de fontes imagéticas visuais.

Similaridades serão demonstradas por meio do diálogo de fotografias, imagens aéreas e etnografias, que sinalizam diferentes escalas de percepção da cidade de Imperatriz-MA, com as perspectivas ecológicas de autores como Robert Park, Ernest Burguess, Roderick $M$ ackenzie e com o Interacionismo de Erving $\mathrm{G}$ offman. Seja para compreender os processos de crescimento das cidades ou as relações face a face, tais autores utilizam variáveis espaciais de localização, relacionadas aos tipos de habitação e disposições dos corpos, para delinear e classificar grupos. T rata-se de um processo que objetiva compreender os delineamentos e fronteiras que geram as formações grupais na cidade.

Seguindo essa lógica, o presente texto está organizado em duas seções, nas quais serão trabalhadas: 1) a relação entre as análises visuais e a Escola de Chicago; e 2) a exposição de uma narrativa visual sobre a cidade de Imperatriz, na qual serão executados três níveis de abordagem: análise de imagens de satélite e plantas urbanas; análise de uma rua; e, por fim, análise de uma situação em uma praça - 
diferentes recortes que possuem princípios similares na relação de variáveis sociais e espaciais.

Espaço, paisagem e interações: uma questão de observação da etnografia imagética

Para problematizar a existência de uma Sociologia do Espaço,Frehse (2008) destaca que as observações sobre a importância do espaço físico para as análises sociológicas é algo antigo e presente em diferentes tradições teóricas, que percebem essa variável como: relacionada à mediação e contradição de determinadas práticas sociais; campo para o desenvolvimento da interação e das representações sociais;e, ainda,enquanto ambiente marcado por dinâmicas de seleção, distribuição e acomodação, ancoradas em uma perspectiva ecológica.

Em relação à hipótese de que Erving Goffman seja um Sociólogo do Espaço, Frehse (2008) percebe que a obra desse autor é, na verdade, influenciada pelas ideias de espaços interacional e social, legadas de Simmel e Durkheim, e também pelas concepções de espaço-físicocenário e espaço físico-condicionante originárias da perspectiva etnográfica e ecológica da E scola de Chicago.

As variáveis espaciais são fundamentais nos processos de compreensão das paisagens, das interações e das interpretações de diversos tipos de fontes imagéticas. $T$ al fato pode ser notado desde os clássicos dasCiências Sociais do século $X I X$, inclusive na teoria sociológica de Durkheim (1999), por meio da qual é possível pensar a dimensão espacial das cidades como resultante de uma série de especializações e divisões do trabalho, que são marcadas pelo adensamento populacional e maior número de relações de interdependência entre os indivíduos. Em outros termos, significa que as formas da cidade, observadas ao longo dos anos, em imagens aéreas e plantas urbanas, vária de acordo com os aspectos de adensamento, especialização e divisões do trabalho.

Para Park (1967), as plantas da cidade estabelecem limites e metas, indicam ordenações, localizações e 0 caráter das construções. Ele nota que, no desenvolvimento do esboço de uma planta urbana, são considerados aspectos como: a geografia física e as facilidades e desvantagens naturais, incluindo os meios de transporte. Ele explica que, no desenvolvimento desse processo:

Crescendo a cidade em população, as influências de simpatia, rivalidade e necessidade econômica mais sutis tendem a controlar a distribuição da população. Comércio e indústria buscam 
localizações

vantajosas

circundando-se de certas partes da população. Surgem quarteirões de residências elegantes, dos quais são excluídas as classes mais pobres em virtude do acrescido valor da terra. Crescem então cortiços que são habitados por grandes números das classes pobres incapazes de se defenderem da associação com marginais e viciados. (PARK, 1967, p.33)

Se essa citação fosse representada com a utilização de uma imagem de satélite, seria possível delinear áreas e compreender alguns sentidos das distribuições por meio das características de cada região, uma operação cujos resultados apresentam algumas similaridades com a ideia de zonas concêntricas, utilizada por Burgess (1948) para compreender o crescimento da cidade. Esse autor propõe a hipótese de que a cidade se organiza e se desenvolve naturalmente por meio de cinco zonas: 1) a central, de comércio; 2) a de transição, que geralmente é invadida pelo comércio ou pelaindústria;3) a de moradias de operários; 4) a de residências de alta categoria; e 5) as commuters- locais suburbanos caracterizados pelo movimento pendular de trabalhadores.

E mbora tenha ocorrido contestação em relação ao padrão espacial das zonas concêntricas e uma confusão entre as noções de distância ecológica e distância linear por parte dos críticos, um aspecto constante, tanto dos seguidores de Burgess quanto dos críticos, são as referências espaciais e geométricas e as diferentes formas de pensar a cidade. Em raciocino próximo a essa ecologia humana, também se destaca Paul Henry Chombart de Lauwe, pela introdução de fotografias aéreas nos estudos urbanos na $F$ rança (FREY, 2001). Em uma escala mais ampla, Santos (2006) contextualiza a noção durkheimiana de solidariedade para pensar as relações espaciais - urbanas e agrícolas - em diferentes relações de complementaridade, hierarquização e semelhança. 0 conjunto de deslocamentos de pessoas, mercadorias, capital e informações nesses espaços geográficos é analisado por Correa (2006) por meio da categoria deinteração espacial.

Sejam quarteirões, sejamzonas concêntricas ou cidades, é possível estabelecer, nas diferentes paisagens, uma relação de equivalência entre variáveis sociais e espaciais, pois os tipos de construção, os tipos de divisões do trabal ho social, de vizinhanças e de grupos de categorias profissionais ou deparentesco constituem fenômenos sociais com características territoriais. Assim, utilizando os próprios termos de Burgess (1948),pode-se dizer que as relações sociais 
estabelecidas dentro de uma indústria possuem projeção nos locais de moradia dos operários, administradores, seguranças e demais classes profissionais que compõem aquele universo. Há uma relação direta entre distâncias espaciais e distâncias geográficas,de forma que as diferenciações no interior da indústria também são manifestadas por meio de um conjunto de características sociais expressas em outros espaços. Trata-se assim de uma questão de distância social (BOGARDUS, 1949) na cidade, ou seja, as questões de aproximação e distanciamento social, diretamente vinculadas às diferenças sociais, são expressas também em ter mos territoriais. Segundo esse autor:

A despeito da proximidade física em que estão as pessoas da cidade, 0 que predomina é a distância social. A falta de simpatia e compreensão que caracteriza a distância social é por toda parte evidente nas cidades. O capitalista e os operários que fazem parte dos sindicatos, que se acusam mutuamente, exibem traços de distância social. 0 rico proprietário e os moradores dos domicílios superlotados e talvez anti-higiênicos pertencentes ao primeiro estão separados por grandes distâncias sociais. 0 pedreiro e a moça que faz a sua estreia na sociedade denotam pouca compreensão um do outro. A gorjeta, que é um costume da cidade, implica distância social, pois raramente uma pessoa dá gorjetas a seus iguais. A gorjeta significa diferença em "status" e, portanto, denota distância social. Os abismos entre os filhos educados na cidade e seus país, entre filhos influenciados pela cidade e seus antepassados educados no campo, estão aumentando. A existência de bandos depredatórios de meninos, de altas taxas de delinqüência juvenil e de ondas de crimes nas cidades constitui um índice de distância social. As lutas entre grupos de raças diferentes são, antes de tudo, fenômenos urbanos que revelam distância social. As descrições da cidade como o lugar mais solitário do mundo são expressões de distância social. (BOGARDUS, 1949, p.42)

A relação entre distância social e geografia, que pode ser observada nos locais de moradia e nos processos de territorialização dos grupos, propicia um caminho interessante para analisar determinadas lógicas e condições que possibilitam a construção de identidades espacialmente delimitadas. Um exemplo disso é citado por Park (1967) quando 
destaca que as distâncias física e sentimental se reforçam entre si e estão relacionadas ao desenvolvimento da organização social na cidade, algo também relacionado à origem étnica ou social. 0 autor explica que toda cidade possui suas colônias raciais como as Chinatowns, em São F rancisco e N ova York e a L ittle Sicily, em Chicago, locais cujas organizações espaciais denotam hábitos, costumes, necessidades e processos de assimilação de suas respectivas populações.

Pode-se dizer que, até o momento, 0 presente texto demonstrou que tais abordagens são focadas nas análises das"estruturas sociais e fenômenos sociais, localizados ou territorialmente delimitados" (WIRTH, 1948, p. 976).Em linha semelhante, é possível utilizar o termo ecologia interacional, 0 qual, segundo Quinn(1948), se refere a

problemas tais como:(1) localização típica de áreas funcionais dentro de uma cidade, enquanto estas dependerem de processos ecológicos; (2) localização de vilas, pequenas cidades e cidades grandes em relação às suas áreas de hinterland, salvo quando estas dependerem diretamente de fatores do meio físico; (3) número de lojas e serviços dentro de áreas típicas, segundo se relacionam tanto com a população consumidora quanto entre si em cadeias funcionas; e (4) invasões e sucessões típicas de populações em funções que resultam de interação ecológica. (QU I N N,1948,p.89)

A ecologia interacional (QUINN, 1948), ao considerar as localizações, funções, concentrações e relações entre diferentes populações, sustenta-se sobre princípios de análise das distâncias sociais (BOGARDUS, 1949), reforçando a importância de compreendermos os entrelaçamentos de variáveis sociais e espaciais como pedra fundamental nos estudos dos grupos urbanos. Assim, retomando a hipótese de que, independentemente das escalas e perspectivas, as análises com imagens são orientadas visualmente por referências espaciais, defende-se que há uma relação direta entre o processo de interpretação dessas questões durante 0 trabalho de observação direta e 0 de interpretação e produção de imagens como fotografias, imagens de satélite, plantas da cidade e outras das mais diferentes escalas.

Contra a artificialidade da separação de variáveis e análises especializadas, acredita-se que haja um continuum entre condicionantes sociais e espaciais de produção dos territórios urbanos e que estes podem ser percebidos de diferentes formas e em uma variedade 
de fontes, tratando-se assim mais de um princípio analítico do que de um conjunto conceitual mais complexo. A esse respeito, tentaremos demonstrar que processos de territorialização só acontecem, porque determinadas distâncias e interações conseguem imprimir nitidez e formas nas paisagens e espaços urbanos. Nesse sentido, o método visual seria uma possibilidade de apreender esses aspectos e problematizar uma abordagem que já vem sendo utilizada, ainda que de modo silencioso; pois, como percebe $M$ artins (2012, p.35): "M esmo sem o recurso imagético e interesse pela fotografia, a Sociologia devotada aos processos sociais cotidianos passou a trabalhar com descrições sociológicas intensamente visuais."

Dentro do contexto de explicação da utilização da fotografia na Sociologia, José de Souza Martins esclarece que, embora essa área tenha possuído um interesse tardio pela fotografia, sempre houve descrições visuais nos trabalhos etnográficos de autores clássicos relacionados à Escola de Chicago, nos quais 0 componente imagético era produzido a partir das narrativas que possibilitavam ao leitor visualizar cenários, atores, relações e condutas da vida diária etc. Assim, busca-se demonstrar que tais formas, narradas e observadas, se materializam em localizações espaciais, que, segundo os temos de Durkheim e M auss (2001),são diretamente atreladas às representações sociais do mundo sensível.

Narrativas sobre espaços e grupos na cidade de Imperatriz-M A

Localizada na região Sudoeste do M aranhão, situada de forma equidistante das capitais mais próximas ${ }^{1}$, a cidade de Imperatriz é a segunda maior cidade do estado, com uma população que, em 2010, era de 247.505 mil habitantes, e cuja estimativa para 2016 é de 253.873 mil habitantes (IBGE, 2016). A história do crescimento territorial dessa cidade está diretamente relacionada com as navegações ocorridas no rio Tocantins durante a segunda metade do século XIX e a construção da BR 010, conhecida também como a Belém-Brasília, no final da década de 1950.

Em uma primeira observação feita na literatura local ${ }^{2}$, nas imagens aéreas e de satélite e também nas estruturas de edificações de diferentes localidades da cidade, foi possível verificar que o sentido do crescimento urbano da cidade tem sido para L este: do rio Tocantins, ultrapassando a atual BR 010. Por meio dos estudos de Orlando Valverde e Caratina Vergolino Dias (1967), obtiveram-se os registros da planta da cidade nos anos de 1938 e 1960. Informações que apresentam os dois 
momentos citados inicialmente: o primeiro, da relação da cidade com o rio; e o segundo, de quando a expansão urbana a conectou à rodovia. $\mathrm{Na}$ primeira planta, aparecem os traçados das ruas 15 de novembro, Coronel $M$ anoel Bandeira e Godofredo Viana. Já na segunda, de 1960, tem-se a rua Bom Futuro e um vazio na área que corresponde aos atuais bairros Juçara, Três Poderes, MaranhãoNovo e N ova I mperatriz.

A té 1950, a cidade resumia-se a três ruas paralelas ao rio Tocantins, mas expandiu-se durante essa década por conta de um fluxo migratório e da produção de arroz. Sobre esses dois aspectos, Franklin
(2012) explica que, durante o "ciclo do arroz", iniciado na referida década, ocorreu a chegada de contingentes populacionais de vários estados do Nordeste. Segundo ele:

Nos cinco primeiros anos dessa década, segundo o Censo do IBGE de 1960, o município de Imperatriz recebeu 4.247 migrantes, quase a metade de toda a sua população à época, o que incluía o distrito de Montes Altos, emancipado em 1955.

Nos três anos seguintes ao Censo, chegaram mais 7.536, mais que dobrando a população municipal

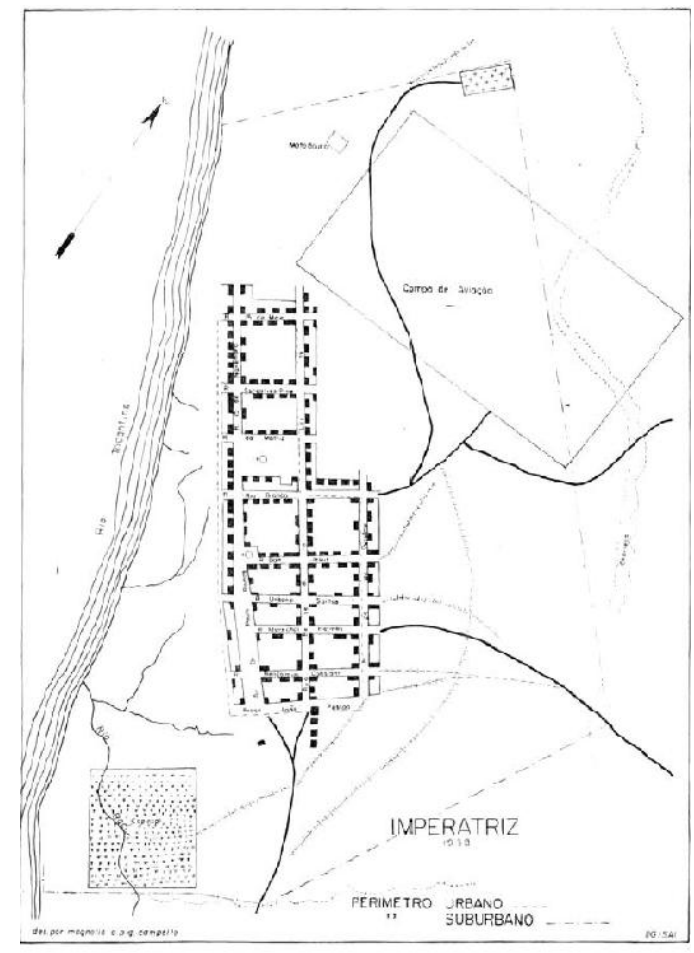

Mapa $\mathrm{xxT1}$

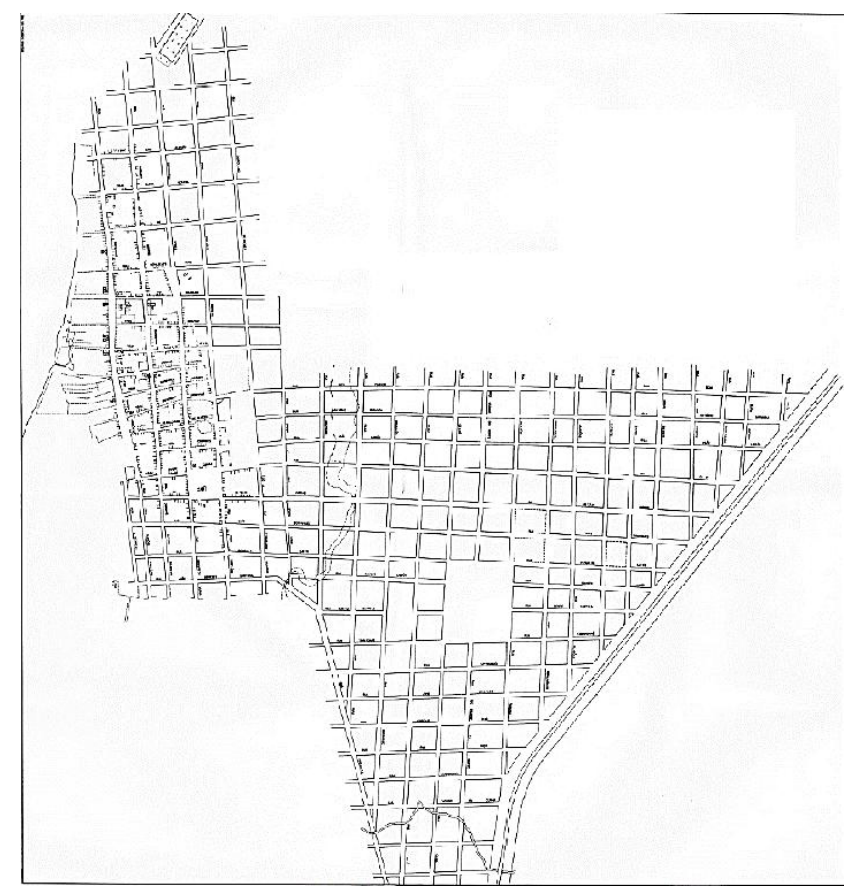

I magens1 e 2 - Plantas da cidade de I mper atriz em 1938 e 1960. Fonte: Valverde; D ias (1967, p.203 e 205)

ESPAÇ O E C ULTU RA, UERJ, RJ, N . 40, P. 133-156, JU L./DEZ. DE 2016

http://www.e-publicacoes.uerj.br/index. php/espacoecultura/ 
existente antes do início da construção da Rodovia Belém Brasília. (F RAN KLIN , 2008, p.128)

Esse autor explica que a alta produção de arroz favoreceu o comércio local, que passou a ser marcado também pela atividade de transporte e beneficiamento desse cereal, resultando em um total, no final da década de 1960 , de mais de duas dezenas de usinas de beneficiamento de arroz, instaladas primeiramente nas proximidades da "F arra Velha", região próxima ao Centro, e no bairro $M$ aranhão $N$ ovo, próximo à rodovia Belém-Brasília. A primeira corresponde à área próxima às três primeiras ruas da cidade, e a segunda, até a década de 1990, era considerada um subúrbio distante do Centro ${ }^{3}$.

Em caminhadas pelas ruas João Lisboa, no Centro, e Mario Andreaza, no bairro $M$ aranhão Novo, é possível ainda observar sinais daqueles tempos áureos de produção e beneficiamento de arroz. Nas ruas citadas anteriormente, respectivamente, registram-se a "U zina Tocantins" (Imagem 3) e outra usina de beneficiamento (Imagem4). É importante ressaltar que, no caso da segunda usina observada, nota-se que a paisagem urbana é composta por uma série de edifícios que, segundo Noleto (2012), representam um momento de explosão imobiliária e verticalização que marcou a cidade durante a década de 1980. Trata-se, assim, de uma paisagem que mescla passado e presente, mais especificamente: estruturas produtivas da década de 1950 e conjuntos verticalizados (Imagem4) que emergiram na área a partir da década de 1980.

Ao dialogar sobre os tempos antigos dessa região com uma moradora do conjunto Sunset Boulevard (primeiro
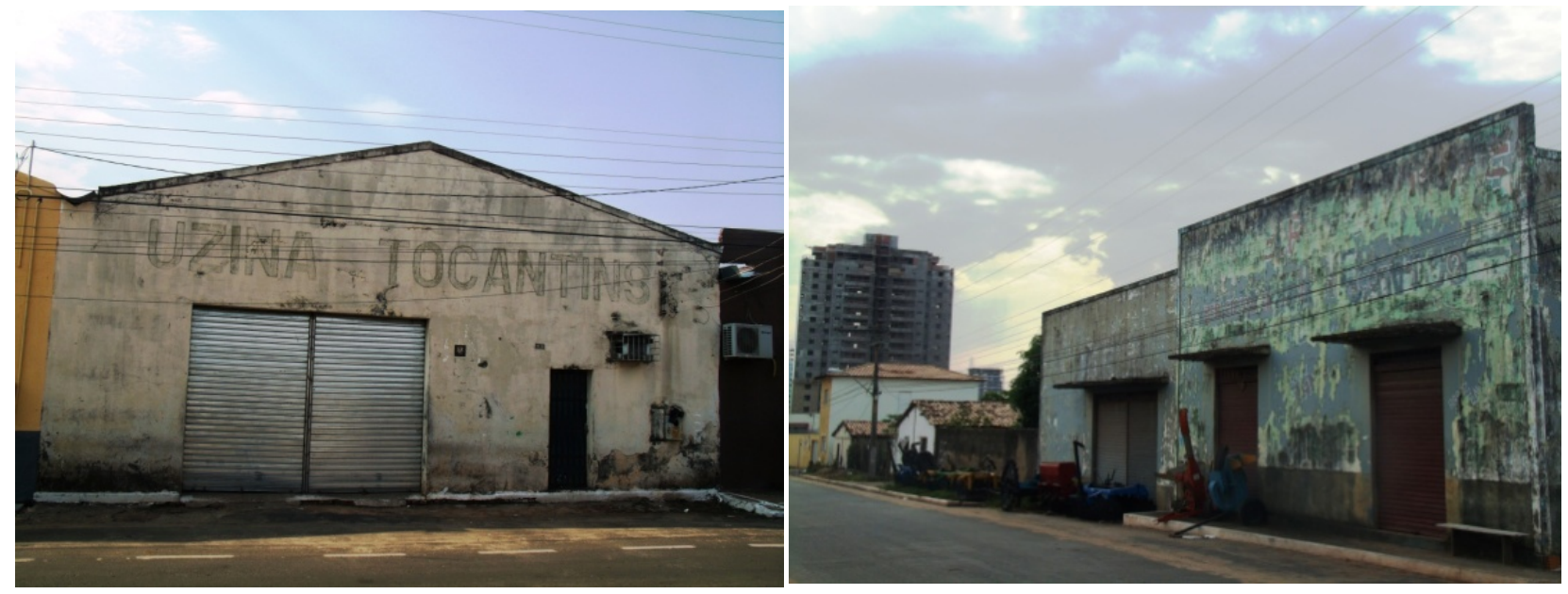

I magens 3 e 4 - U zina Tocantins e U sina de beneficiamento de arroz. Fonte: Pereira (2015). 
conjunto vertical de Imperatriz), obteve-se a seguinte descrição do bairro $M$ aranhão Novo: "Aqui era menos povoado e considerado bairro dos ricos, porque a maioria tinha transporte. Aqui, nunca passou ônibus, nem táxi-lotação ${ }^{4}$. Só moravam os considerados com o poder aquisitivo bom" (Informante A, 29 de julho de 2016). Além de fornecer um panorama do bairro $M$ aranhão Novo no final da década de $1980^{5}$, a moradora deixa muito clara uma ideia de distância social, apontando assim uma relação direta entre território e características da comunidade local.
A observação da paisagem urbana da cidade de Imperatriz demonstra uma série de temporalidades e formas de ocupação que certificam a existência de uma dinâmica de local izações orientada por lógicas sociais, culturais e também por processos estruturais da história e da economia regional ${ }^{6}$. Para compreender um pouco as mudanças nas localizações, utiliza-se também uma imagem de satélite extraída do Google Earth (Imagem5), que demonstra bem a localização do centro comercial e de um conjunto de bairros de I mperatriz em relação ao rio Tocantins e à rodovia Belém- Brasília.

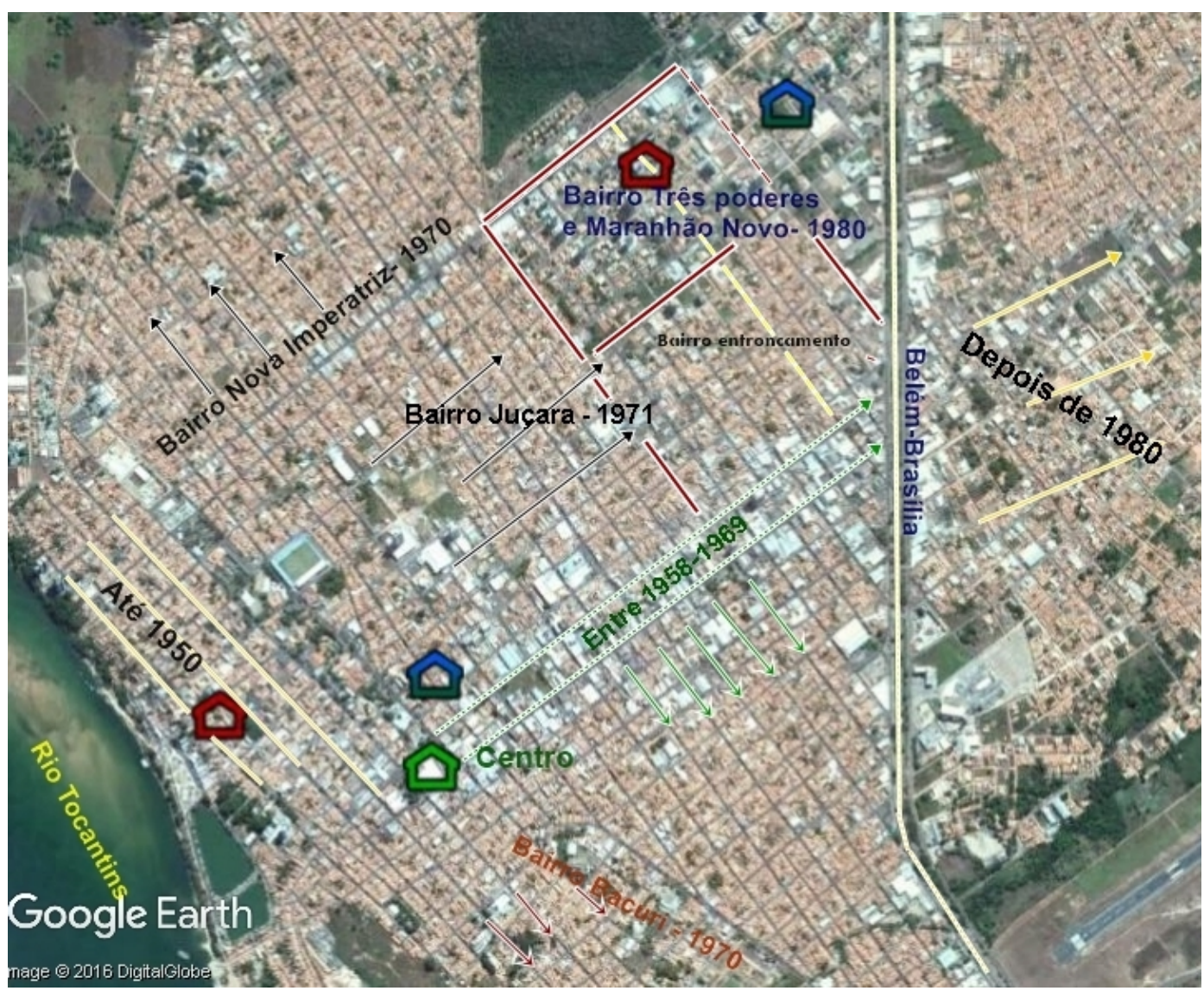

I magem 5 - Algumas datas e observações sobre o espaço urbano de I mperatriz. Fonte: G oogle E arth, 2016.

ESPAÇ O E CULTU RA, UERJ, RJ, N . 40, P. 133-156, JU L./DEZ. DE 2016

http://www.e-publicacoes.uerj.br/index.php/espacoecultura/ 
A I magem 3 sinaliza as localizações de elite, as usinas de beneficiamento de arroz e os sentidos de crescimento dos bairros nas diversas décadas, reforçando a ideia de movimento e de interação entre as localizações urbanas. Prova disso são as casinhas vermelhas que representam localizações residenciais de elite em diferentes períodos (até 1950 e em 1980). Elas demonstram 0 deslocamento de valores e tendências entre bairros da cidade e, às vezes, dentro do próprio bairro, como é o caso de algumas famílias do Sunset Boulevard (conjunto da década de 1980), que passaram a habitar edifícios mais verticalizados e "modernos". A necessidade de diferenciação e distância social parece ser um elemento fundamental para compreender as lógicas que influenciam as localizações das elites imperatrizenses.

Tanto as casinhas azuis, que representam as usinas de beneficiamento, quanto às vermelhas indicam um dos sentidos de crescimento urbano da cidade de Imperatriz - diferenciação e distanciamento da primeira área central. As duas setas verdes sinalizam as avenidas Dorgival Pinheiro e Getúlio Vargas, construídas entre 1958 e 1969, que reforçam que o objetivo principal, da administração pública, daquele período era ligar o sítio urbano da cidade a rodovia Belém-Brasília.
Essas vias propiciaram a construção de uma série de ruas paralelas com nomes de estados (setas verdes), dispostas de forma perpendicular à referida avenida. Ao longo dessas avenidas de ligação, também ocorreu à expansão da área comercial que, de forma setorizada, apresenta: áreas de lojas de produtos agropecuários e automotivos, localizadas próximas à Belém-Brasília; lojas de móveis, roupas e eletrodomésticos, nas quadras próximas à cidade; e bancos e hotéis espal hados ao longo das avenidas.

Se a cidade for pensada em termos de zonas concêntricas, pode-se dizer que os bairros surgidos depois da década de 1980 , ou seja, após a construção da rodovia, e os que surgiram ultrapassando o limite da Avenida Bernardo Sayão possuem algumas semelhanças com as commuters, pois é das vias que ligam tais locais ao centro comercial que vem o maior fluxo de automóveis, por conta dos trabalhadores que se deslocam de suas residências para os locais de trabal ho, lazer etc..

De modo geral, a Imagem 5 mostra que há diferenças nas formas dos terrenos. Por exemplo, os bairros construídos após a Belém-Brasília não apresentam um padrão ordenado de organização e formas dos terrenos, como é possível observar nas áreas próximas ao aeroporto. Já no outro Iado da rodovia, os terrenos do $M$ aranhão Novo e doT rês Poderes apresentam mais 


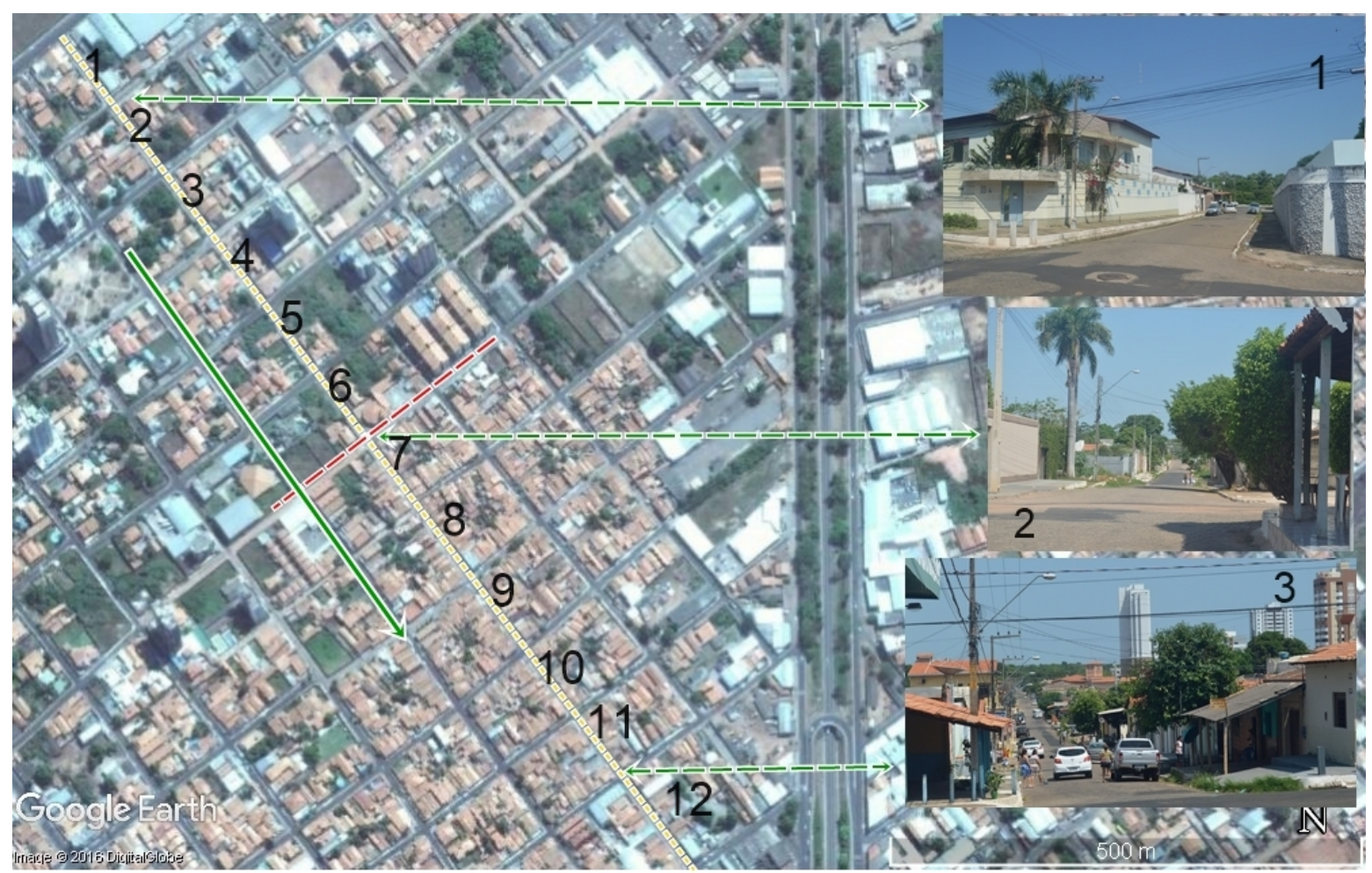

I magem 6- T rajeto da caminhada. F onte: G oogle E arth, 2016.

áreas verdes e um padrão definido em grandes quadras. Se há uma distinção no tamanho dos terrenos e nas casas, isso possui também implicações como diferenciação nas densidades populacionais e sociabilidades desenvolvidas no local. A fim de verificar tal relação entre forma de ocupação e relações sociais, foi realizada uma caminhada ao longo da rua $\mathrm{G}$ uanabara (destacada por uma seta amarelana I magem 6), atentando para as formas como essa rua muda de características ao longo do seu trajeto.

A o conhecer a cidade de Imperatriz, essa rua, por ser bem representativa do processo de ocupação da década de 1980 , chama a atenção. Para quem trabalha no
Centro e mora mais próximo à $\mathrm{BR} 010$, a parte mais populosa dela constitui uma opção de trajeto para o trabalho, pois transmite uma ideia de segurança por apresentar uma boa movimentação e presença de pessoas circulando também durante o período noturno. No entanto, a mesma rua possui um trecho localizado no bairro nobre dos T rês Poderes que, apesar de ser composto por grandes casas fincadas em grandes terrenos e também por um bom número de terrenos vazios, 0 que 0 torna deser to e perigoso.

Para realizar uma análise mais sistemática, foi realizada uma caminhada pela manhã ao longo do trajeto da referida rua, durante a qual notou-se que, a partir 
de determinado limite (sinalizado pela linha vermelha - Imagem 6), ocorre uma mudança de características, já que uma parte é mais deserta e outra, mais movimentada. Há, de fato, uma diferenciação na forma como são expressas as relações de vizinhança, o que levou a um questionamento sobre a influência de fatores como os tamanhos dos terrenos e as características das moradias nos processos de sociabilidade local.

A partir do trabalho de campo, construiu-se o Quadro 1, no qual é detalhado o que foi visualizado. Até a quinta quadra, havia 29 residências e 9 terrenos baldios. É importante ainda destacar que, dessas 29, apenas 17 possuem portas e garagens que dão acesso à rua Guanabara, pois muitas residências localizadas nas esquinas possuem seus portões para as transversais. Pelas características habitacionais observadas, nota-se que fatores como: 0 número de terrenos vazios e de as portas voltadas para as avenidas e ruas perpendiculares favorece um menor tráfego de moradores pela rua Guanabara. Nesse trecho, 0 número de casas também é bem menor do que o registrado a partir da sétima quadra. Para fazer um comparativo, na sétima

\begin{tabular}{|c|c|c|c|}
\hline & $\begin{array}{l}\text { Casas e } \\
\text { terrenos }\end{array}$ & $\begin{array}{l}\mathrm{N}^{\circ} \text { de } \\
\text { acesso à } \\
\text { rua por } \\
\text { quadra }\end{array}$ & Estabeleciment os comerciais \\
\hline $1^{2}$ Quadra & $\begin{array}{l}6 \text { casas }(2 \\
\text { terrenos })\end{array}$ & 1 & Apenas cons truções residenciais. \\
\hline $2^{2}$ Quadra & $3(1$ terreno $)$ & 2 & Apenas cons truções residenciais. \\
\hline $3^{2}$ Quadra & $7(1$ terreno $)$ & 7 & Apenas cons trucoões residenciais. \\
\hline $4^{2}$ Quadra & 3 (1 terreno) & & Apenas cons truções residenciais. \\
\hline $5^{2}$ Quadra & 5 (3 terrenos) & 3 & Apenas cons trucoões residenciais. \\
\hline $6^{2}$ Quadra & 5 & 4 & 1 igreja. \\
\hline $7^{2}$ Quadra & $22(1$ terreno $)$ & 21 & $\begin{array}{l}1 \text { restaurante, } 1 \text { loja de venda de polpas de fruta, } \\
1 \text { salão de beleza e } 1 \text { bar. }\end{array}$ \\
\hline $\mathrm{S}^{2}$ Quadra & 26 & 26 & 1 bar e 1 supermercado. \\
\hline $9^{2}$ Quadra & 27 & 27 & $\begin{array}{l}1 \text { padaria, } 1 \text { barraca de venda de lanche,1 } \\
\text { lanchonete, } 1 \text { loja de venda de cerveja, 2 } \\
\text { mercearias e } 1 \text { farmácia. }\end{array}$ \\
\hline $10^{2}$ Quadra & 24 & 24 & $\begin{array}{l}2 \text { mercearias, } 2 \text { lanchonetes, } 1 \text { galeto, } 1 \text { açougue, } \\
1 \text { salão de beleza e } 1 \text { loja automotiva. }\end{array}$ \\
\hline $11^{2}$ Quadra & 19 & 19 & $\begin{array}{l}2 \text { restaurantes, } 1 \text { loja de webdesign, } 1 \text { bar } \text { e } 2 \\
\text { mercearias. }\end{array}$ \\
\hline $12^{2}$ Quadra & 24 & 24 & $\begin{array}{l}9 \text { lojas de produtos automotivos e } 6 \text { comércios } \\
\text { variados }\end{array}$ \\
\hline $13^{2}$ Quadra & 20 & 20 & 20 lojas especializadas em produtos automotivos. \\
\hline
\end{tabular}

Quadro 1- Características estruturais das áreas da rua G uanabara. Fonte: Pereira, 2016.

ESPAÇ O E CULTURA, UERJ, RJ, N . 40, P. 133-156, JU L./DEZ. DE 2016

http://www.e-publicacoes.uerj.br/index.php/espacoecultura/ 
quadra, que é precedida pela sexta, com suas 5 casas, foram contabilizadas 22 casas, com suas portas e janelas voltadas para a própria rua Guanabara. Nas quadras seguintes, 0 número chega a 27 habitações, significando um maior número de casas $^{7}$ com menor espaço, maior número de famílias e maior possibilidade de contato social entre os moradores.

Além de apresentar, aparentemente, uma densidade maior, o setor a partir da sétima quadra oferece um número de opções de serviços e estabelecimentos comerciais que 0 diferencia totalmente do aspecto residencial das primeiras seis quadras. $\mathrm{Na}$ realidade, a partir da sexta quadra, é possível observar uma série de elementos com capacidade de gerar concentração e atrair pessoas. Por exemplo, a Igreja Católica Santa Clara e várias opções de restaurantes e lanchonetes, que também atraem pessoas dos bairros adjacentes. Nesse sentido, uma relação interessante entre as duas áreas é a dos operários da construção civil que trabalham na área nobre, nas edificações no Três Poderes e $\mathrm{M}$ aranhão N ovo, e se alimentam na parte mais popular e de maior densidade populacional. Essa relação torna comum a presença de grupos de homens com macacões azuis e capacetes, caminhando no sentido da sétima quadra em diante. Por outro lado, também existem moradores da parte mais popular que realizam compras em um grande supermercado localizado no bairro T rês Poderes.

Sobre a Imagem7, é importante dizer que a família registrada veio pelo mesmo trajeto selecionado para a experiência de campo. Observados primeiramente na região mais deserta da rua Guanabara, foram logo identificados

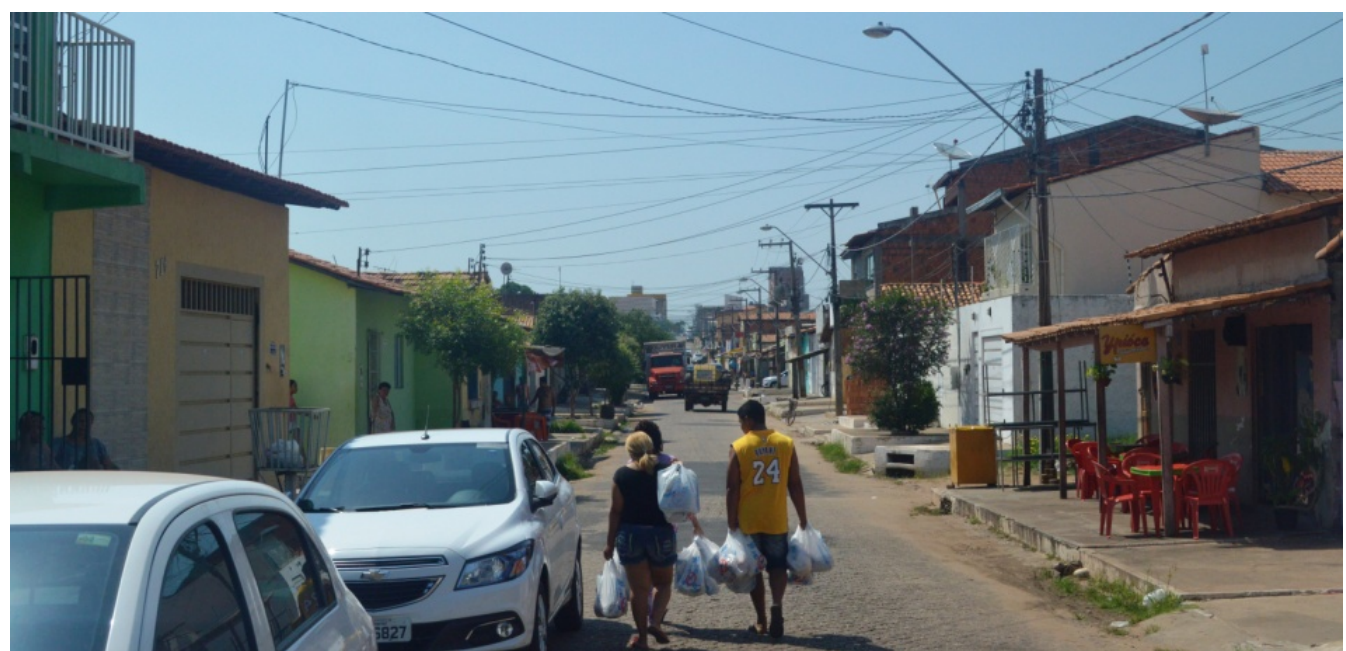

Imagem 7 - M oradores das áreas populares com as compras feitas no bairro vizinho.F onte: Pereira, 2016. 


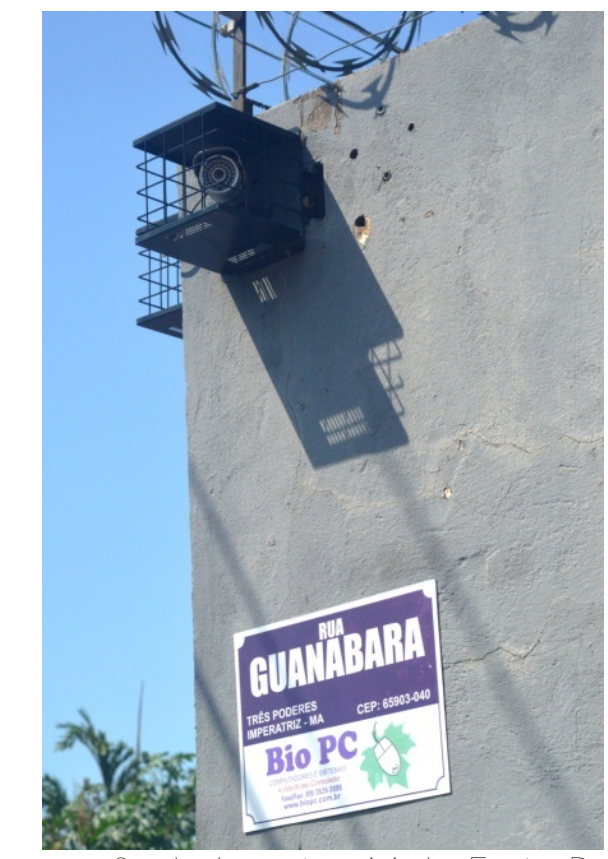

I magem 8 - I solamento e M edo. Fonte: Pereira, 2016.

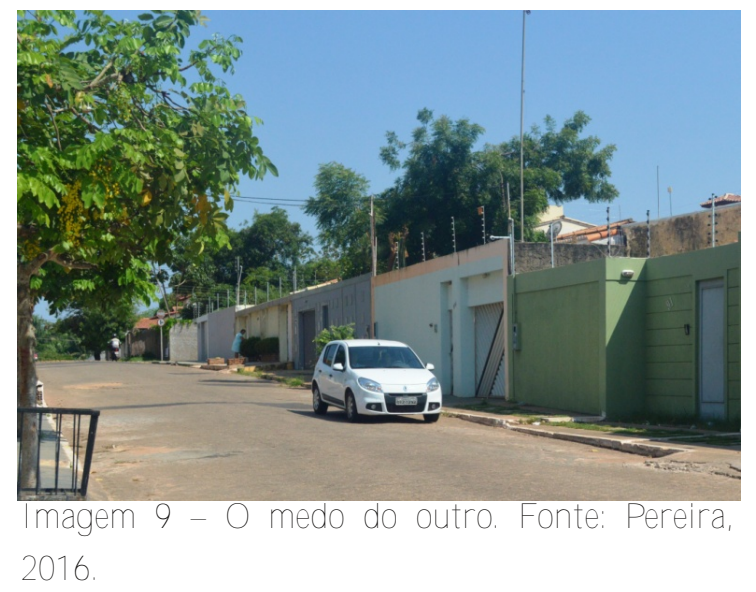

como moradores locais, que, ao chegaram à parte mais densa da rua, se misturaram entre as cores e pequenas casas.Como é possível notar nas fotografias extraídas de três pontos distintos do trajeto (I magem 5), há uma diferenciação no número de pessoas e carros nas duas ár eas.

A influência da densidade e das características físicas locais sobre as formas de sociabilidade e interação foi presenciada na própria experiência de campo: por um lado, por conta do sentimento de medo que surgiu ao transitar com máquina fotográfica pela parte mais deserta da rua; por outro, pela reciprocidade dos comportamentos de desconfiança vivenciados na relação pesquisador - morador.

$N$ as Imagens 8 e 9, é possível notar a presença constante de cercas elétricas, câmeras de segurança e arames farpados. U ma situação interessante também diz respeito ao próprio processo de registro fotográfico da I magem 9 , realizado em um contexto no qual uma senhora saiu de casa para jogar água nas plantas em frente à residência e em que um carro branco ficou parado por algum tempo para, somente em seguida, fazer manobra para entrar na residência, ações que aconteceram assim que 0 pesquisador se retirou do local de onde foi possível capturar 0 ângulo presente na I magem 9.

Nesse contexto, qualquer pessoa com câmera fotográfica em mãos e cader no de campo para a realização de anotações, provavelmente, pode ser identificada tanto como um sujeito estranho e ameaçador para os moradores daquele ambiente e/ ou como uma possível vítima de assaltantes a ser rendida e levada para os terrenos vazios mais próximos. 
Já da sétima quadra em diante, ocorre uma experiência diferenciada com os moradores. Nos dois primeiros contatos, uma mulher morena que chegou pela esquina da quadra e adentrou na terceira ou quarta casa dali cumprimentou 0 pesquisador, que também foi aconselhado por uma senhora que estava sentada na porta de casa com a filha a não tirar fotos no local de onde estava vindo pelo fato de lá ser uma área perigosa, embora seja considerado um local sofisticado.

Poucas casas depois, um casal estava sentado em cadeiras na porta de casa(I magem10), ouvindo reggaes, que são mais comuns na ilha de São Luís - M A. A o receberem a explicação de que estava sendo feito um levantamento da quantidade de casas no local para pensar algo que relacione violência e quantidade de pessoas na rua, o senhor informa que mora ali há 20 anos e reafirma a mensagem dada pela primeira senhora. M ais adiante, na quadra seguinte, duas senhores, após perguntarem 0 que pesquisador está fazendo por ali e receberem a explicação, são questionadas sobre como era aquele local antes. U ma delas, chamada Regina, diz que mora lá desde 1986 e que naquele tempo não havia casas pelo lado do T rês Poderes. Ela informou que só havia três casas e mato para todos os lados. A outra diz que os terrenos vazios são um perigo, pois têm atraído assaltantes e dependentes químicos; ela declara ainda que, apesar de o lado nobre ser mais deserto e perigoso, os assaltos também têm ocorrido naquele trecho mais movimentado.

0 tratamento e as relações na parte mais densa da rua ocorreram mais facilmente do que na parte mais nobre. Em certo momento, ao parar para beber uma água mineral, um homem que bebia cerveja no bar ofereceu novamente um alerta ao pesquisador sobre o perigo de transitar com a máquina fotográficas naquele local. A aproximação dos registros fotográficos sinaliza um tipo de entrosamento que provavelmente jamais ocorreria no outro setor da rua Guanabara. A aproximação ocorreu sem a desconfiança presente naexperiênciade outrora e de forma mais natural, chegando ao ponto de um morador se aproximar e pedir para sair na foto da paisagem da rua, situação representada na Imagem 11.

M esmo que não tenham sido coletados muitos elementos sobre as biografias dos atores em questão, é possível inferir que as localizações e situações foram decisivas nos processos de interação, reforçando a ideia da interdependência entre variáveis sociais e espaciais.

A experiência parece retomar alguns aspectos dos estudos de Emilio W illems, pois, segundo M endonza (2005), esse autor, ao estudar a cidade de São Paulo, partiu de algumas hipóteses: 1) os 


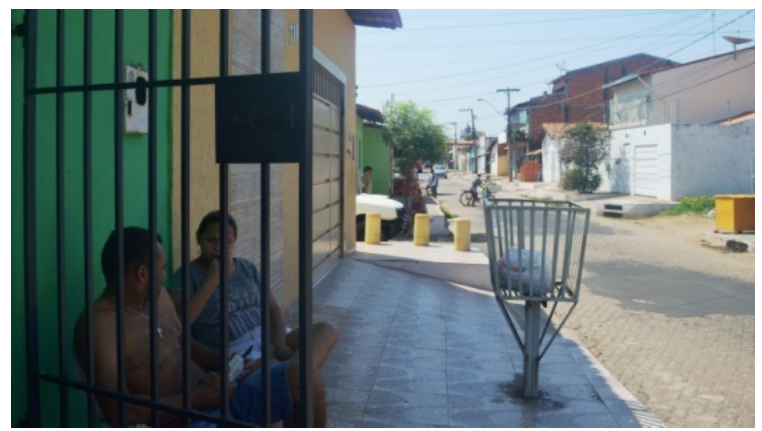

Imagem 10 - Casal na porta de casa Fonte: Pereira, 2016.

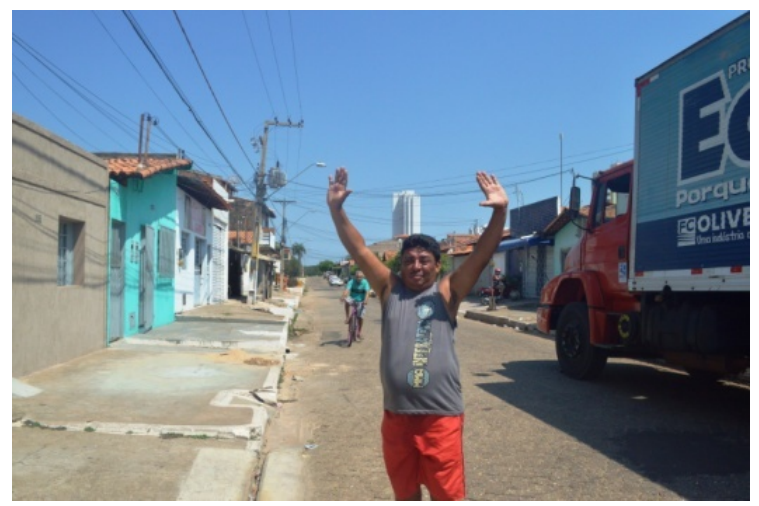

Imagem 11 - M orador pede para ser fotografado.

Fonte: Pereira, 2016.

moradores de bairros residenciais da alta burguesia possuíam certo desprezo pelas relações vicinais, reforçando processos de segregação social e distinção social; 2) as casas de pequena e média burguesia não possuíam áreas internas, o que favorecia a agregação e contatos mais frequentes com a rua; e 3) no caso das habitações proletárias, há a preponderância de solidariedade e sociabilidade, embora os conflitos sejam mais frequentes.

De fato, a sociabilidade na parte mais densa da rua Guanabara é verificável de modo mais fácil, pois algumas casas possuem janelas e portas em contato direto com a rua. Além disso, é normal observar pessoas em frente às casas ou nas esquinas conversando. Durante a noite, esse fluxo de pessoas é otimizado por conta do número de lanchonetes e bares localizados nessa parte da rua. De modo geral, é possível perceber dois padrões de organização e ocupação espacial que são marcados por formas específicas de apropriação. Parafraseando Park (1967), pode-se dizer que cada setor assumiu as características dos próprios habitantes, seja nos investimentos materiais, seja na relação com a rua e com os vizinhos. 0 tamanho, a concentração de casas e a distribuição são variáveis fundamentais para compreender essas tramas sociais materializadas nos espaços da rua Guanabara.

Se é possível notar que há uma lógica de diferenciação dos espaços em relação à distância social, que pode ser percebida nos diferentes tipos de bairros e nas formas como as características espaciais destes podem orientar as interações, crê-se que os mesmos princípios podem ser observados em fenômenos sociais de menor escala. Dessa forma, pretende-se demonstrar que as plantas da cidade, as diferentes lógicas presentes nas relações entre bairros e as interações entre atores sociais em um determinado espaço público podem ser analisadas segundo uma perspectiva que considere as interações como frutos de variáveis espaciais e de 
localização e em relação aos aspectos sociais e históricos observáveis nas mais diferentes formas de imagens.

Para exemplificar esses princípios analíticos com mais nitidez em relação às interações face a face, descrevem-se al gumas observações diretas e registros fotográficos realizados na Praça de Fátima ${ }^{8}$, espaço público notabilizado a partir de um conjunto de interações cotidianas. Destaca-se um acontecimento do dia 24 de outubro de 2014, quando um grupo de capoeiristas que ia participar do II Encontro Nacional de Capoeira em Imperatriz-MA formou uma roda de capoeira na referida praça.

Por volta das 9 horas da manhã, foi possível observar que muitos ol hares da praça se direcionavam ao grupo composto majoritariamente por crianças e alguns adultos e jovens que tocavam berimbau e percussão e direcionavam as atividades dos capoeiristas. Em pouco tempo,havia uma concentração de pessoas assistindo aos jogos de capoeira. Vendedores, transeuntes, funcionários públicos, crianças acompanhadas dos pais, adolescentes e até um senhor que trabalhava em umas das farmácias próximas à praça compunham 0 grupo de observadores. Sobre aquela situação, foi feito o seguinte registro no Caderno de Campo:

O contato com os capoeiristas foi facilitado por um dos membros do grupo que me autorizou a tirar fotos e a ficar à vontade. Rodeada de pessoas filmando, tirando fotos e interagindo, a roda de capoeira gerou uma concentração e a divulgação de um evento de capoeira que iria acontecer na cidade. Aquela concentração mobilizou os olhares das pessoas que não passavam de alguns hippies e trabal hadores locais e contou com a presença de uma equipe da imprensa televisiva. Naquele contexto, um farmacêutico tirou 0 sapato e entrou na roda e começou a jogar também. A jornalista entrevistava 0 mestre responsável por tudo aquilo e um de seus alunos me convidava para ficar mais próximo para realizar os registros. As ações dos alunos mais velhos sinalizavam o desejo de divulgação do grupo, de manutenção da ordem das atividades e deproteção das crianças capoeiristas. (Caderno de Campo, 30/ 10/2014)

Nessa concentração de pessoas, foi possível perceber uma espécie de limite territorial construído pelo grupo de capoeiristas. U ma fronteira que ficou mais nítida, quando ocorreu a aproximação de dois mendigos, um homem e uma mulher, que na época permaneciam perambulando pelos espaços da Praça de Fátima. Naquela 
situação, o homem, trajando camisa verde, bermuda e boné, começou a tentar realizar 0 movimento de ginga, fora da roda; enquanto a mulher, trajando camisa amarela, transitava de um lado para outro, ao redor do grupo, mas de forma mais contida.

Logo que foi notado pelo grupo (I magem 12), o homem passou a ser vigiado e era possível observar que sempre tinha um jovem capoeirista ao seu lado (I magem 13). E mbora se trate de uma situação social de curta duração, já que, logo que finalizaram as apresentações, todos voltaram para seus afazeres cotidianos, foi muito evidente 0 estabelecimento de distância social entre os atletas os mendigos. Ao mesmo tempo em que ocorreu uma negociação de significados entre as pessoas admiradoras do esporte, as fronteiras foram "desenhadas" no momento do evento e logo redesenhadas de acordo com o cotidiano da praça após o evento.

Enfim, tanto a situação da Praça de F átima quanto o cotidiano da parte de maior densidade - a partir da sétima quadra - da rua Guanabara possuem uma capacidade de atração e centralização de pessoas, característica ecológica essa que, segundo M ckenzie (1948), está diretamente relacionada à satisfação de interesses comuns dos grupos humanos, tais como educação, trabalho, diversão e outras necessidades, e tambémao processo pelo qual a comunidade é formada, pois, ao se reunirem em determinados lugares para

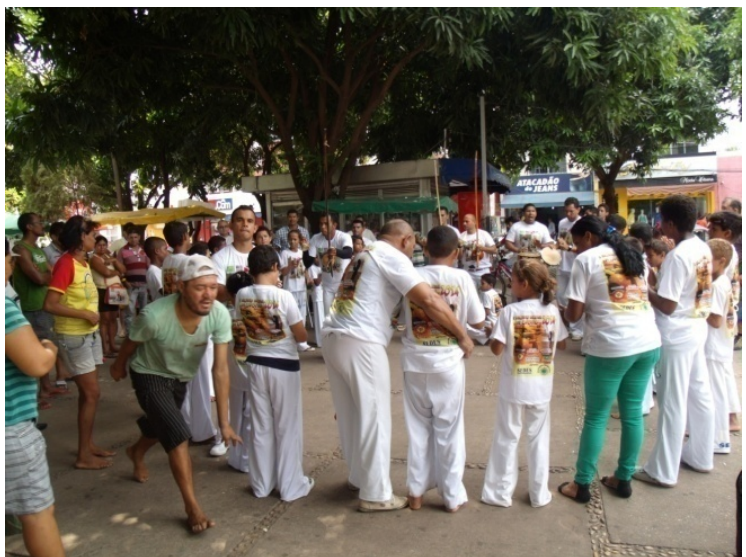

Imagem 12 - Jovem observando pessoa em situação de rua. Fonte: Pereira, 2016.

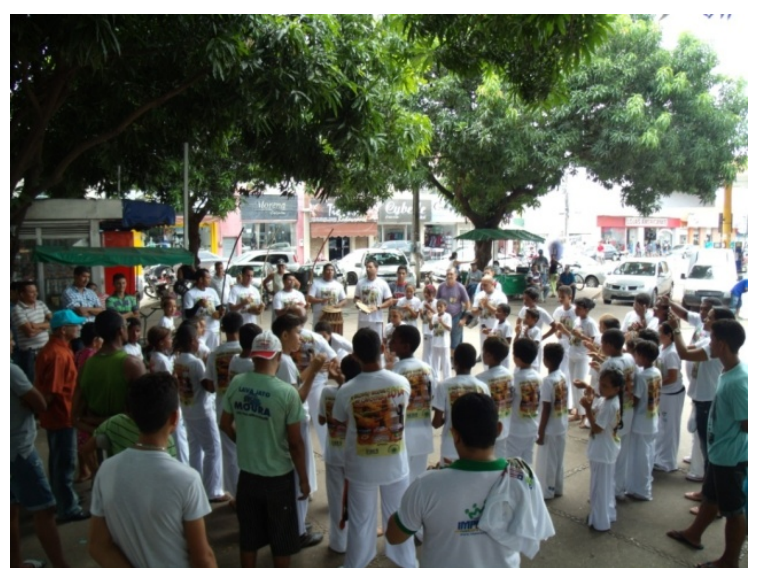

Imagem 13 - Definição de limites. Fonte: Pereira, 2016.

buscar a satisfação de seus interesses, os sujeitos delineiam uma base territorial para a determinação dos grupos.

Nesse sentido, as relações associativas e de vizinhança nos dois setores analisados anteriormente e na situação de interação complexa ocorrida na roda de capoeira podem ser problematizadas também em relação aos tipos de necessidades dos membros e à forma como elas são satisfeitas (nas esquinas, bares e 
espaços das partes mais populares da rua Guanabara, no interior das mansões e casarões da parte mais elitizada da mesma rua ou em sua área mais comercial, composta por vários tipos de serviços para automóveis, dentre outros). N esse sentido, a variável espacial é importante no que diz respeito à maior densidade e possibilidade de contato social e também à forma como é apropriada para a satisfação de determinadas necessidades.

Se os limites entre os dois setores da rua Guanabara foram notados segundo as características das habitações observadas na imagem de satélite e na caminhada in loco, cujas informações foram somadas às impressões coletadas durante as interações com os moradores da região, na situação microssociológica observada na praça de Fátima, os limites são observados nas I magens 13 e 14 por conta de características físicas e sociais e de expressões corporais desenvolvidas pelos capoeiristas e pelas pessoas em situação de rua.

Conclusão

Ao pensar o bairro para além do bairro, a cidade em relação à região, os atores em relação aos atores, a pesquisa com imagens, de satélite ou fotográficas, possibilita desenvolver e aprimorar 0 processo de geometrização e a perspectiva relacional, tão cara para uma infinidade de abordagens, que vão desde 0 viés configuracional de Norbert Elias até 0 "cenário" das abordagens interacionistas.

A questão das escalas pode ser materializada em diferentes tipos de imagens que podem ser interpretadas por meio de um conjunto prévio de conhecimentos locais, mas também por meio de uma leitura de imagens enviesada de acordo com o referencial teórico escolhido. No caso do presente texto, fez-se um exercício de pensar a perspectiva ecológica e interacionista, por valorizarem a relação entre aspectos espaciais e sociais.

O sentido do crescimento da cidade, as diferentes interações nos dois setores da rua Guanabara e as interações observadas na praça de Fátima foram notados como importantes exemplos por meio dos quais são observadas dinâmicas sociais de distanciamento e de centralização, processos que podem ser explicados quando são analisadasas estruturas materiais, econômicas e sociais presentes nos referidos espaços.

A proximações, distanciamentos, diferenças e semelhanças são parâmetros essenciais na compreensão das regras do "jogo" das localizações e disposições, sinalizando sempre a tendência de territorialidades, que pode ser mais bem explorada em estudos posteriores. Por meio desses parâmetros, foi possível aprimorar 0 "olhar" para observar as delineações e 
fronteiras em diferentes tipos de fontes imagéticas, tanto na forma como se expressavam na arquitetura e no urbanismo das ruas, quanto nas fachadas dos próprios atores sociais.

Enfim, finalizam-se estas breves reflexões sobre algumas possibilidades de problematização na cidade de Imperatriz, enfatizando a necessidade de transpor os processos de geometrização bachalerdiana para os diferentes tipos de fontes visuais e para a observação em campo, pensando o componente imagético não apenas nas fontes consagradas, mas também no próprio processo cognitivo e etnográfico, por meio do qual é possível analisar as relações entre formas de organização social no espaço e problematizar o espaço organizado por determinados grupos.

\section{Notas}

${ }^{1}$ A cidade fica a $630 \mathrm{~km}$ de São Luís, $595 \mathrm{~km}$ de Belém, $615 \mathrm{~km}$ de T eresina e $628 \mathrm{~km}$ de Palmas.

${ }^{2}$ N oleto (2012); Barros (2012).

3 Jornal 0 Progresso de 14/05/1991: "Ônibus estenderão linhas aos subúrbios: beneficiando os moradores do M aranhão N ovo e Bacuri"

${ }^{4}$ Trata-se de um tipo de taxi que fazer itinerários fixos, pode ser utilizado coletivamente e que possui 0 valor da passagem mais baixo que 0 taxi convencional.

${ }^{5}$ Período da construção do conjunto.
${ }^{6}$ Ao estudar Imperatriz, M acedo (2009) percebeu que a produção do espaço urbano dessa cidade também é influenciada pela realidade regional tocantina e pelo papel da cidade de Imperatriz nesse contexto.

${ }^{7}$ Essas são casas modestas, na maioria, com portas e janelas diretamente ligadas à rua.

8 Tratam-se de um caderno de campo, fotografias e observações vinculadas ao projeto de extensão"P raças do tempo: Cotidiano, imagens e memórias do centro urbano de Imperatriz" executado entre 01/ 09/ 2014 e 01/ 09/ 2015.

\section{Referências bibliográficas}

AURÉLIO. O minidicionário da língua portuguesa. 4a edição revista e ampliada do minidicionário Aurélio. 7 ạ impressão - Rio de Janeiro, 2002.

BACHELARD, Gaston. Discurso preliminar.In: A Formação do Espírito Científico. Editora Contraponto, Rio de Janeiro, 1996.

BOGARDUS, Emory S. Cap. X LI - Distância social na cidade. In: PIERSON, Donald (org.). Estudos de Organização Social. Tomo II: L eituras de Sociologia e Antropologia Social. São Paulo: Livraria M artins Editora S.A ., 1949, pp. 645-652.

BURGESS, Ernest W. O crescimento da cidade: introdução a um projeto de pesquisa. In: Estudos de Ecologia Humana: leituras de Sociologia e Antropologia Social. Donald PIERSON (Org.) Livraria M artins E ditora, São Paulo, 1948.

CORRÊA, Roberto Lobato. Interações espaciais. In: Castro, I. E., Gomes, P. C. C. E Corrêa, R. L. Explorações geográficas: percursos no fim do século. 
Rio de Janeiro: Bertrand Brasil, 2006.

DURKHEIM , É mile. As Causas. IN: DURKHEIM, É mile. Da Divisão do Trabalho Social. Tradução E duardo Brandão. M artins Fontes. São Paulo 1999 (Coleção T ópicos). pp. 251-307

FRANKLIN , A dal berto. A pontamentos e fontes para a história econômica de Imperatriz / Adalberto Franklin. - Imperatriz, M A: Ética, 2008

FREHSE, Fraya. ErvingG offman, sociólogo do espaço. Rev. bras. Ci. Soc. São Paulo , v. 23, n. 68, p. 155-166, Oct. 2008.

FREY, Jean-Pierre. Paul-Henry Chombart de Lauwe :lasociologieurbainefrançaise entre morphologies et structures. IN :Espaces et société, $n^{\circ} 103$ : PaulHenry Chombart de Lauwe et I'histoiredesétudesurbainesen France, Paris, L'H armattan, 2001, pp. 27-55

HOUAISS, Antônio. Dicionário Houaiss da Língua Portuguesa. Rio de Janeiro, E d. Objetiva, 2001.

MCKENZIE, Roderick D. A comunidade Humana abordada ecologicamente. In: Estudos de Ecologia Humana: Leituras de Sociologia e Antropologia Social. Donald PIERSON (Org.) - Livraria Martins E ditora, São Paulo, 1948.

MENDOZA, Edgar S.G..Donald Pierson e a escola sociológica de Chicago no Brasil: os estudos urbanos na cidade de São Paulo (19351950).Sociologias[ online] . 2005, n.14 [ citado 201604-12] , pp.440-470.

NOLETO, Agostinho. Imperatriz: desenvolvimento urbano In: Imperatriz: 160 anos/A cademia I mperatrizense de L etras- I mper atriz,M A A IL ,2012.
PARK, Robert Ezra. A cidade: sugestões para a investigação do comportamento humano no meio urbano.In.: Velho, Otávio. 0 fenômeno urbano. Rio de Janeiro, Zahar, 1979

QU IN N . James A. A hipótese de zonas de Burguess e seus críticos. In: Estudos de Ecologia Humana: Leituras de Sociologia e Antropologia Social. Donald PIERSON (Org.) - Livraria M artins Editora, São Paulo, 1948.

SAMAIN,Etienne (org). Como pensam as imagens. Campinas: E ditora da U nicamp, 2012.

SANT OS, M ilton.A N atureza do Espaço: Técnica e Tempo, Razão e E moção / M ilton Santos. - 4. ed. 2. reimpr. - São Paulo: E ditora da U niversidade de São Paulo, 2006

SOU ZA, Jailson $M$ acedo de. A cidade na região e a região na cidade: a dinâmica socioeconômica de Imperatriz e suas implicações na região tocantina. Imperatriz/ M A : Ética, 2008

VALVERDE, Orlando; DIAS, Catarina Vergolino. A rodovia Belém-Brasília: estudo de geografia regional. Rio de Janeiro: F undação Instituto Brasileiro de G eografia, 1967. 


\title{
NOTES ON THE RELATIONSHIP BETWEEN SOCIAL VARIABLES AND SPATIAL ORGANIZATION: A RESEARCH EXPERIENCE IN THE CITY OF IMPERATRIZ-MA
}

\begin{abstract}
THIS ARTICLE BRINGS REFLECTIONS AND OBSERVATIONS CONCERNING THE USE OF DIFFERENT TYPES OF VISUAL SOURCES TO CONSIDER SOME POSSIBILITIES OF INTERPRETATION ON URBAN GROUPS AND SECTORS OF THE CITY OF IMPERATRIZ-MA. THROUGH A NARRATIVE GUIDED BY THEORIES THAT EMPHASIZE THERE LATIONSHIP BETWEEN SPATIAL AND SOCIAL VARIABLES, WE USED A SET OF PHOTOGRAPHS, DIALOGUES WITH LOCALS AND DIRECT OBSERVATIONS TO INTERPRET APPROACHES, DISTANCES AND CONCENTRATIONS THAT MAKE UP THE URBAN DYNAMICS OF THIS CITY, CONSIDERED THE SECOND LARGEST IN THE STATE OF MARANHÃO. THINKING THE CITY ACCORDING TO THREE SITUATIONS, SCALES AND LEVELS, THERE IS A NEED TO THINK GEOMETRIZATION LOOK FOR MANY DIFFERENT TYPES OF SOURCES AND SITUATIONS PUT IN ETHNOGRAPHIC DO.
\end{abstract}

KEYWORDS: GEOMETRIZATION; SCALES; PICTURES; URBAN GROUPS. 


\section{NOTAS SOBRE LA RELACIÓN ENTRE VARIABLES SOCIALES Y ORGANIZACIÓN ESPACIAL:}

UNA EXPERIENCIA DE INVESTIGACIÓN EN LA CIUDAD DE IMPERATRIZ-MA

RESUMEN: EL PRESENTE ARTÍCULO TRAE REFLEXIONES Y OBSERVACIONES ACERCA DEL USO DE DIFERENTES TIPOS DE FUENTES VISUALES PARA PENSAR ALGUNAS POSIBILIDADES DE INTERPRETACIÓN SOBRE GRUPOS URBANOS Y SECTORES DE LA CIUDAD DE IMPERATRIZ-MA. A TRAVÉS DE UNA NARRATIVA ORIENTADA POR TEORÍAS QUE PRIVILEGIAN LA RELACIÓN ENTRE VARIABLES ESPACIALES Y SOCIALES, SE UTILIZÓ UN CONJUNTO DE FOTOGRAFÍAS, DE DIÁLOGOS CON MORADORES Y OBSERVACIONES DIRECTAS PARA INTERPRETAR APROXIMACIONES, DISTANCIAMIENTOS Y CONCENTRACIONES QUE CONSTITUYEN LA DINÁMICA URBANA DE ESA CIUDAD, CONSIDERADA LA SEGUNDA MAYOR DEL ESTADO DE MARANHÃO. PENSANDO LA CIUDAD DE ACUERDO CON TRES SITUACIONES, ESCALAS Y NIVELES, SE VERIFICÓ LA NECESIDAD DE PENSAR LA GEOMETRIZACIÓN DE LA MIRADA HACIA LOS MÁS DIFERENTES TIPOS DE FUENTES Y SITUACIONES PUESTAS EN EL HACER ETNOGRÁFICO.

PALABRAS CLAVE: GEOMETRÍA. ESCALAS. IMÁGENES. GRUPOS URBANOS. 